\title{
REPRESENTAÇÕES SOBRE A HONRA E A SEXUALIDADE FEMININA NO LIVRO V DAS ORDENAÇÕES FILIPINAS: O ESTATUTO JURÍDICO DA MULHER NO DIREITO PORTUGUÊS DO PERÍODO COLONIAL
}

\author{
Vanessa Caroline da Cruz ${ }^{1}$ \\ Mestranda em História Social (UEL) \\ Prof $^{\mathrm{a}}$ Dr $^{\mathrm{a}}$ Silvia Martins de Souza (Orientadora)
}

O presente trabalho tem como objetivo investigar o estatuto jurídico da mulher no Direito Português, utilizando como fonte o Livro V das Ordenações Filipinas, importante conjunto de leis que buscavam definir regras para as mais variadas matérias jurídicas, tendo vigorado em Portugal, Espanha e suas respectivas colônias, sendo que, no Brasil, sua vigência se estendeu até o século XIX, vendo-se substituído apenas após a elaboração do Código Civil Brasileiro. Nele está presente uma série de títulos que cristalizam representações sobre o gênero feminino, prevendo a criminalização dos atos que não se adequassem às condutas aí referenciadas como desejáveis e corretas. Estas imagens idealizadas sobre o comportamento feminino produzidas na metrópole foram transplantadas para a América Portuguesa, e insistentemente reiteradas pelos discursos canônico, inquisitorial e das autoridades coloniais, apresentando grande relevância na construção das identidades de gênero no Brasil. Dessa forma, tendo em vista a forte relação estabelecida entre o comportamento moral/sexual e a concessão de direitos às mulheres, buscaremos compreender as representações sobre a honra e a sexualidade feminina nele constituídas, utilizando como metodologia uma leitura da fonte feita a contrapelo em uma análise interdisciplinar entre história, gênero e direitos.

Palavras-chave: Gênero; Ordenações Filipinas; Estatuto Jurídico da Mulher.

\section{INTRODUÇÃO}

Nas últimas décadas, sobretudo a partir de 1980, a relação entre a História e o Direito tem se renovado, distanciando-se da abordagem clássica feita através da história do direito, disciplina destinada à formação de juristas, e transformando-se em um "campo de estudos da história intelectual e institucional". Segundo Lara e Mendonça (2006), os direitos e justiças constituem-se enquanto frutos das conflituosas relações construídas socialmente em condições históricas, geográficas, econômicas e culturais específicas, não representando um corpo coeso de regras imutáveis, mas uma série de preceitos legais posta em jogo na arena das múltiplas interpretações, retomadas, negações e (re) apropriações feitas pelos sujeitos no transcorrer do processo histórico.

Pesquisas recentes têm ressaltado a importância de se compreender o Direito como resultado das relações sociais, não mais como um campo associado unicamente a ideias e filosofias, mas com toda a dinâmica dos processos históricos. Para as autoras: "há algum tempo o direito já aparece como um produto social, e sabe-se que os valores, os textos e as normas jurídicas estão diretamente relacionados com os ritmos do processo social” (LARA; MENDONÇA, 2006, p. 9).

\footnotetext{
${ }^{1}$ E-mail: cruzvanessac@gmail.com.
} 


\section{SEMINÁRIO DE PESQUISA EM CIÊNCIAS HUMANAS - SEPECH \\ Humanidades, Estado e desafios didático-científicos \\ Londrina, 27 a 29 de julho de 2016}

É importante considerar, conforme apontam as referidas autoras, que os elementos judiciais não são um corpo coerente de regras, podendo comportar diferentes noções de direito, no espaço e no tempo, e também ser utilizadas para propósitos diferentes daqueles para os quais foram criados. Destacam ainda que estes figuram na sociedade não apenas como um instrumento de repressão e de poder exercido de cima para baixo, mas como um campo onde se instauram batalhas entre os mais diversos atores sociais por suas concepções de direito, legitimidade e justiça, e mesmo que uma determinada concepção destes valores seja cristalizada em forma de leis, esta luta continua estabelecida na interpretação dada pelos sujeitos a estes princípios quando lançam mão do recurso formal a estas mesmas leis (Op. cit.).

Considerando essa perspectiva, buscaremos aqui resgatar brevemente a trajetória percorrida pelas concepções jurídicas adotadas em Portugal desde o período formativo do Estado até o período dos governos absolutistas, nos quais foram promulgadas as Ordenações do Reino (Afonsinas, Manuelinas e, por fim, as Filipinas) e investigar quais as principais concepções culturais a respeito da honra e da sexualidade feminina foram habilmente orquestradas para constituir o chamado estatuto jurídico da mulher no Direito Português, especificamente no que se refere às Ordenaçôes Filipinas.

O Direito Português e, consequentemente, aquele aplicado nas terras da América portuguesa, está baseado sobre diversas tradições que dialogam e divergem entre si. Entre elas, podemos destacar o Direito Romano, o Direito Canônico, os costumes locais próprios a cada região de Portugal, relacionados às tradições jurídicas dos povos germânicos que passaram a se instalar na Península Ibérica a partir do século $\mathrm{V} \mathrm{d}$. C., o Direito Comum e ainda as chamadas Ordenações do Reino, que representam o esforço de constituição de uma lei de validade nacional, reforçando a construção do rei como dispensador da justiça, no contexto da ascensão dos Estados Absolutistas na Europa (SANTOS, 2007).

A formação do Estado Português desenvolve-se propriamente após o período da Reconquista (século XII d. C.), definido por Azevedo (2013) como o momento da retomada, por parte dos cristãos, do território ibérico conquistado por muçulmanos em 711. O contexto das disputas territoriais trouxe uma série de peculiaridades ao medievo português, que não apresenta o "florescimento do feudalismo à maneira da França, Alemanha e Inglaterra" (p. 129). Entre essas peculiaridades, podemos citar a constituição de povoados formados por pequenos proprietários livres, dando margem, posteriormente ao nascimento dos concelhos e municípios. Nas aldeias, havia características próprias e definidas, sendo que, em alguns casos, era possível aos habitantes não apenas não adotar o regime de servidão, mas dispor das terras que possuíam como quisessem e ainda eleger livremente o seu senhor.

É neste contexto que se formará o reino português, bem como o seu direito, no qual sobram influências provenientes dos costumes germânicos, trazidos pelos visigodos; dos direitos canônico e romano, que mais se acentuarão a partir de meados do século XIII; dos elementos hebraico e muçulmano, que em considerável número habitavam a península (AZEVEDO, 2013, p. 131).

Segundo Azevedo, em fins do século XII, o direito "era então essencialmente privilégio, estampando-se nos foros da nobreza, nas prerrogativas do clero, nos forais 


\title{
XI SEMINÁRIO DE PESQUISA EM CIÊNCIAS HUMANAS - SEPECH \\ Humanidades, Estado e desafios didático-científicos \\ Londrina, 27 a 29 de julho de 2016
}

dos concelhos, nos costumes dos senhorios, nos estatutos das universidades, nos direitos dos mercadores e das demais profissões e atividades", em função do "particularismo dos regimes jurídicos empregados". Neste contexto, dá-se a chamada "redescoberta" do Direito Romano, que trará uma grande renovação para o Direito Português, fornecendo ainda, junto com o Direito Canônico, importantes subsídios para o desenvolvimento do Direito Comum (AZEVEDO, Op. Cit. p. 137 e ss.).

\begin{abstract}
Ambos, Direito Romano e Direito Canônico, vão fornecer os fundamentos do 'Direito Comum', que se expandirá por toda a Europa, sendo acolhido com loas pelos soberanos, desejosos de fortalecer seus poderes diante dos senhores feudais; tanto a tradição imperialista do Direito Romano quanto o ius novum dos canonistas atendiam aos anseios dos governantes, pois melhor se destinavam a afastar as distorções produzidas pelo direito estratificado e privilegiado que até então se aplicara, substituindo-o por outro, mais criterioso e eficaz e, sobretudo, de caráter comum, geral, unitário (Idem, p. 138).
\end{abstract}

Com a ascensão da Dinastia de Borgonha, já no século XII, dá-se impulso ao chamado Renascimento do direito Romano. De acordo com André (s/d), essa tradição não chegou a ser totalmente abandonada na história portuguesa. Entretanto, neste período, ele ganha força e passa a servir de fonte subsidiária ao Direito Português, por meio da adoção do Direito Justinianeu - Corpus iuris Civilis, obra organizada pelo imperador Justiniano entre 528 e 558 d. C. e das chamadas glosas a estas fontes. Nesta iniciativa, que ficou conhecida como Escola dos Glosadores, destacam-se as obras de Acúrsio, autor da Magna Glosa, que exerceu influência jurídica em toda a Europa (SANTOS, 2007).

A Escola dos Comentadores, também conhecida como Escola de Bartolo, caracteriza-se pelo uso do comentário como método interpretativo, diferenciando-se da glosa, que se restringia apenas à explicação gramatical de verbetes de difícil entendimento. "Para alcançar o sentido do texto, o comentador utilizava o método dialético ou escolástico que visava, através de sucessivas análise e síntese, a superação de aparentes contradições e a construção de um sistema lógico" (SANTOS, 2007, p. 95).

Desta base, acrescida das contribuições do Direito Canônico, sobre o qual falaremos a seguir, constitui-se o Direito Comum, "que servirá de inspiração para a ciência jurídica em toda a Europa até a época do Iluminismo". "Em sentido diverso do 'direito comum' estavam os 'direitos próprios', que eram os ordenamentos jurídicos de origem de cada reino, tendo como fonte geralmente o costume, mas que assumiam grande relevância, face às circunstâncias locais de cada reino" (ANDRÉ, s/d, p.5).

A existência de uma ampla gama de fontes de direito com normas de padrões culturais diferentes dificultava a aplicação da justiça e a administração do país, levando ao surgimento das Ordenações do Reino, promulgadas periodicamente a partir do século XV, que tinham como objetivo "reunir em uma única fonte, atualizada, o Direito vigente da época" (Idem, p. 5).

Segundo Velasco: 


\title{
XI SEMINÁRIO DE PESQUISA EM CIÊNCIAS HUMANAS - SEPECH \\ Humanidades, Estado e desafios didático-científicos \\ Londrina, 27 a 29 de julho de 2016
}

\begin{abstract}
A multiplicidade de normas jurídicas (representada pelos foros e cartas de foral, pelas disposições do direito justinianeu e canônico, pelos capítulos das Cortes, Leis régias, etc.) e as contradições originadas dessa multiplicidade (dificultando sobremaneira a administração da Justiça), foram a causa imediata das Ordenações portuguesas (VELASCO, s/d, p. 17).
\end{abstract}

O estabelecimento do Direito Comum e da autoridade das Ordenações encontrará inúmeros obstáculos pela frente, devido, sobretudo, à força das leis locais, à resistência das comunidades face ao Direito Régio e ao reconhecimento da validade dos princípios regionais por parte dos magistrados. Santos (2007) afirma que as Ordenações possuíam parco alcance e poder de penetração, devido ao analfabetismo dos juízes e à formação destes nas universidades de acordo com o Direito Romano, que somadas aos demais obstáculos ora relacionados, foram entraves significativos ao bom andamento da aplicação das leis monárquicas. Para fomentar o exercício desta e paulatinamente expandir seu uso, buscar-se-á estabelecer aos juízes e legisladores uma hierarquização entre as fontes do direito: dava-se primazia à lei nacional, seguida pelo costume, desde que este não infligisse os princípios instituídos pelas Ordenações e apenas em casos omissos pelo direito pátrio, observam-se os direitos canônico e romano (Op. cit., 2007).

\section{O ESTATUTO JURÍDICO DA MULHER NO DIREITO PORTUGUÊS}

Fortemente influenciado por livros religiosos, o Direito Português quase não chega a se diferenciar do discurso da Igreja no que se refere à mulher. Assentado sobre o modelo que dividia o gênero feminino entre honestas e devassas, Marias e Evas, o estatuto jurídico conferido a esta população pode ser definido pela ideia da suposta inferioridade do sexo feminino, imputando, assim, aos homens, a tutela sobre suas mulheres (SANTOS, 2007).

O Direito Canônico tem grande reverberação sobre as imagens idealizadas sobre as mulheres produzidas pela sociedade portuguesa, uma vez que esta, devido a sua formação cristã, organizava-se de maneira "onde aquele direito regulava situações da vida social que, atualmente, são de competência do Estado". Sua força era tamanha devido ao fato de que o Direito Canônico era utilizado como fonte de direito em todos os reinos cristãos (ANDRÉ, s/d, p 4 e ss).

Neste sentido, o poderio da Igreja Católica aliado a não separação formal entre Igreja e Estado, trazia à baila um olhar moralizante, que estava longe de considerar homens e mulheres como seres iguais. Dessa forma, a imagem da mulher segundo o imaginário jurídico português passava por ideias como a fraqueza mental e física, a debilidade intelectual, a luxúria, a indignidade e a ignorância. Delas retira-se o postulado de que precisariam e, mais do que isso, deveriam ser tuteladas e protegidas de sua maior "tendência ao vício" (SANTOS, 2007, p. 115).

O paradigma da suposta perdição da humanidade através de Eva revela-se um estigma para a interpretação das mulheres não só nos textos sagrados admitidos pela tradição cristã, mas também para o direito e para as culturas populares. A reiterada ideia da culpa e da debilidade feminina mediante o modelo do comportamento daquela que 


\section{SEMINÁRIO DE PESQUISA EM CIÊNCIAS HUMANAS - SEPECH \\ Humanidades, Estado e desafios didático-científicos \\ Londrina, 27 a 29 de julho de 2016}

teria sido a primeira mulher parece ter como objetivo promover a tese da tão propalada "menoridade feminina" (DEL PRIORI, 1993; SANTOS, 2007).

Segundo esta tese, as mulheres permaneceriam eternamente menores, necessitando dos cuidados do homem mais próximo, que lhe valeria em sua falta de racionalidade e debilidade física. Ela não só estava amplamente difundida na sociedade, mas se fazia fortemente presente entre os magistrados e juristas de toda a Europa durante o século XVI:

\footnotetext{
Juntamente com os camponeses e dementes, as mulheres eram consideradas como não legalmente responsáveis por seus próprios atos e não poderiam ser compelidas a aparecer perante uma corte, sendo que em todos os casos seus testemunhos eram considerados menos críveis que os dos homens. Essas ideias levaram os juristas em muitas partes da Europa a recomendar, em certos casos a implantar, a reintrodução da guarda baseada no gênero: mulheres adultas solteiras e viúvas estavam novamente sob tutela masculina e proibidas de tomar qualquer decisão financeira, nem mesmo doações para instituições religiosas, sem sua aprovação (SANTOS, 2007, p. 118).
}

No direito, campo dominado exclusivamente por homens à época, o "status legal da mulher" é secundário. No que figura ser um mundo feito apenas por e para homens, "o feminino é em geral irrelevante, sendo denotado pelo masculino", exceto em matérias que se aplicavam às mulheres de forma específica, como a matéria dos dotes e das heranças. Entretanto, é preciso notar que esse mundo ideal construído pelos juristas nem sempre pode ser notado na prática, onde inúmeras delas exerciam papéis diversos daqueles para elas projetados, movimentando-se numa ampla gama de possibilidades que escapavam ao esforço normativo. Conforme afirma Santos, o direito, sobretudo o direito comum que se tenta implantar a partir das Ordenações do Reino (Afonsinas, Manuelinas e, posteriormente as Filipinas), possuem caráter prescritivo: refletem mais o desejo dos legisladores e magistrados do que a realidade (SANTOS, 2007, p. 118).

Segundo Fernandes (2000), no "Libro Primero del Espejo de la princesa Christiana", o autor defende "a pertinência e a importância de a Rainha poder legislar em matérias relacionadas com o 'mundo feminino', 'aconselhar o marido, regir y governar as las mujeres de sus tierras y señorio, formular ordenações e pragmáticas válidas para todas as mulheres do reino (p. 114)"'.

Entretanto, embora essa possa parecer uma posição progressista e que demonstra a liberalidade com que as mulheres se moviam dentro do reino, a autora supracitada lista as virtudes atribuídas à mulher no século XVI: clemência e misericórdia, devoção e temor de Deus, procurar a Deus com diligência, zelo, curiosidade, amor conjugal, humildade, submissão, vergonha, silêncio, negação do ócio, apego aos afazeres domésticos, entre outros. A castidade, destaca-se, era virtude considerada básica no comportamento feminino (p. 114).

\section{A FIGURA FEMININA NAS ORDENAÇÕES DO REINO}

Constituída nos tempos de União das Coroas Ibéricas (1580-1640), quando Portugal foi governado por reis espanhóis, devido à vacância do poder deixado pelo 


\section{SEMINÁRIO DE PESQUISA EM CIÊNCIAS HUMANAS - SEPECH \\ Humanidades, Estado e desafios didático-científicos \\ Londrina, 27 a 29 de julho de 2016}

desaparecimento do jovem rei D. Sebastião em expedição ao Marrocos, e da morte de seu tio, o Cardeal D. Henrique, que assumira o trono português durante a ausência do sobrinho, dando fim ao reinado da dinastia dos Avis, as Ordenações Filipinas são marcadas pela tradição do Direito Português, com raras interferências espanholas. (Cf. ASSIS, RAMOS, SANTOS, 2004; LARA, 1999).

A iniciativa de reorganização dos códigos legais utilizados por Portugal foi implantada por Filipe I, que empreendeu os primeiros esforços para a elaboração de uma nova "sistematização legislativa" perpetuada pelo filho, Filipe II, após sua morte. Seguindo a estrutura adotada pelos códigos anteriores ${ }^{2}$ as Ordenações Filipinas são compostas por cinco livros, assim divididos: o livro I versava sobre direitos e deveres dos magistrados e oficiais de justiça; o segundo rezava sobre a relação entre Estado e Igreja; o livro III regulamentava as ações cíveis e criminais; o IV falava sobre o direito público e privado ou das pessoas e das coisas e o $\mathrm{V}$ abordava o direito penal, fixando delitos e suas respectivas punições. Os livros, por sua vez, eram divididos em títulos, e estes em parágrafos e artigos (LARA, Ibidem).

O Livro V das Ordenações Filipinas constitui-se como uma fonte rica e propícia à análise com recorte de gênero, pois nele está presente uma série de títulos que dizem respeito às representações sobre mulheres e homens construídas a partir do olhar daqueles que elaboraram as Ordenações, prevendo ainda, a criminalização dos atos que não se adequassem à conduta aí referenciada como ideal. Nele podemos perceber as atribuições feitas socialmente aos gêneros feminino e masculino nos séculos XVI e XVII, isto é, podemos analisar:

[...] a criação inteiramente social das ideias sobre os papeis próprios aos homens e às mulheres. "O 'gênero' sublinha também o aspecto relacional entre as mulheres e os homens, ou seja, que nenhuma compreensão de qualquer um dos dois pode existir através de um estudo que os considere totalmente em separado" (SOIHET, 1997, p. 279).

Dentre estes títulos, podemos encontrar os que se remetem, por exemplo, às punições devidas ao que "dorme com a mulher, que anda no Paço, ou entra em casa de alguma pessoa para dormir com mulher virgem, ou viúva honesta, ou escrava branca de guarda"; ao "homem que casa com duas mulheres, e da mulher, que casa com dois maridos"; aos "alcoviteiros, e dos que em suas casas consentem as mulheres fazerem mal de seus corpos", entre outros (LARA, 1999, p. 106-123 passim).

As punições previstas nestas e em outras situações não eram leves. Ao contrário, elas previam desde pagamento de multa até o degredo e o açoite em praça pública chegando, em alguns casos, à morte. De acordo com Maria Fernanda Bicalho, este rigor referente aos crimes e suas respectivas punições, presentes nas Ordenações Filipinas,

\footnotetext{
${ }^{2}$ Conforme apontam diversos autores, houve em Portugal uma série de códigos anteriores, que figuravam como corpo referencial de normas e regras desse país, organizados periodicamente desde meados do século XV, como as Ordenações afonsinas, as Ordenações manuelinas, o Código sebastiânico, entre outros. Ver: LARA, Silvia Hunold (org.). Ordenações Filipinas. Livro V. São Paulo: Companhia das Letras, 1999. ASSIS, RAMOS, SANTOS. A figura do herege nas Ordenações manuelinas e nas Ordenações Filipinas Justiça \& História, Porto Alegre, v. 4, n. 7,2004. PIMENTEL, Helen Ulhôa. A ambiguidade da moral colonial: casamento, sexualidade, normas e transgressões. Univ. FACE, Brasília, v. 4, n. 1/2, p. 29-63, jan./dez. 2007.
} 


\section{SEMINÁRIO DE PESQUISA EM CIÊNCIAS HUMANAS - SEPECH \\ Humanidades, Estado e desafios didático-científicos \\ Londrina, 27 a 29 de julho de 2016}

teria o sentido de inspirar o temor, servir de exemplo e, ao mesmo tempo, de restaurar a função do rei como árbitro supremo no campo da justiça. Desta maneira, conclui Bicalho: "As Ordenações são preciosos testemunhos do poder de intromissão e de regulamentação por parte da Coroa nas menores esferas e nas mais insólitas condutas e comportamentos dos súditos" (BICALHO, 2000, p. 225).

Aplicadas e interpretadas de forma desigual, conforme a posição social e os privilégios de que eram possuidores os transgressores, as ilegalidades e punições previstas neste código visavam à reafirmação do poder absoluto do monarca sobre seu reino e, sobretudo sobre seus súditos, mesmo nos assuntos hoje considerados de foro íntimo, dando ao rei a chance de exercer seu poder e, quando oportuno, demonstrar benevolência e misericórdia (LARA, 1999).

Conforme Pimentel:

Esse Código, considerado por muitos como "monstruoso", é capaz de revelar a concepção de justiça própria à monarquia absolutista que se impunha e a criação de suas normas, estabelecendo hierarquias sociais com peculiar percepção de punição. Assim, a aplicação da justiça não se dedicava a extinguir comportamentos inadequados da mesma maneira para todos, ou seja, a inadequação de comportamentos não era uma concepção universalizada. A alguns era dado o direito de transgredir, a outros a justiça significava imposição de rótulos, de sinais discriminadores. A nova ordem que se impunha exigia que o rei mostrasse todo o seu poder no topo de hierarquias sociais que deveriam estar bem visíveis e estabelecidas (PIMENTEL, 2007, p. 30). Espaçamento simples

Todos os títulos observados abordam práticas que se encontram fortemente carregados pela ideia da tentativa de "resguardar" as mulheres, sobretudo "virgens e viúvas honestas", do contato com a presença masculina, relacionando a moral feminina diretamente ao seu comportamento sexual, onde mulher honrada é igual a dizer mulher pudica. Esta concepção está expressa em alguns dos artigos que se seguem:

Todo homem, de qualquer qualidade que seja, que dormir com alguma mulher que andar em nossa casa ou casa da rainha, ou do príncipe, perderá toda sua fazenda, a metade para nossa Câmara e a outra para os cativos. [...] E sendo provado que alguma pessoa entrou em casa de outro para dormir com mulher livre que nela estivesse, por qualquer maneira que seja, se o morador da casa for escudeiro de linhagem ou cavaleiro e a pessoa que the entrar na casa for peão, seja açoitado e degredado cinco anos para o Brasil com baraço e pregão (LARA, p. 98, 1999).

No título 18, lê-se ainda:

Todo homem, de qualquer estado e condição que seja, que forçosamente dormir com qualquer mulher, posto que ganhe dinheiro por seu corpo ou seja escrava, morra por isso. [...] E a mesma pena haverá qualquer pessoa que para a dita der ajuda, favor ou conselho (Idem, p. 103). 


\title{
XI SEMINÁRIO DE PESQUISA EM CIÊNCIAS HUMANAS - SEPECH \\ Humanidades, Estado e desafios didático-científicos \\ Londrina, 27 a 29 de julho de 2016
}

Há também, neste sentido, uma especial preocupação em salvaguardar a figura masculina que tem autoridade sobre essas mulheres não casadas, caso as mesmas sejam violadas dentro do lar anfitrião:

E o homem que induzir alguma mulher virgem ou honesta que não seja casada, por dádivas, afagos ou prometimentos e a tirar e levar fora da casa de seu pai, mãe, tutor, curador, senhor ou outra pessoa sob cuja governança ou guarda estiver, ou de qualquer outro lugar onde andar ou estiver por licença, mandado ou consentimento de cada um dos sobreditos, ou ela assim enganada e iludida se for a certo lugar donde a assim levar e fugir com ela, sem fazer outra verdadeira força a ela ou aos sobreditos, e o levador for fidalgo ou pessoa posta em dignidade e honra grande e o pai da moça for pessoa plebeia e de baixa maneira ou oficial, assim como alfaiate, sapateiro ou outro semelhante, não igual em condição nem estado, nem linhagem ao levador, o levador será riscado de nossos livros e perderá qualquer tença graciosa ou em sua vida que de nós tiver e será degredado para a África até nossa mercê. (LARA, Ibidem).

Embora com as Ordenações Filipinas tenha havido um significativo distanciamento entre o Direito Canônico e o Direito Civil, por assim dizer, inclusive com a elaboração na América Portuguesa de códigos específicos sobre os crimes religiosos $^{3}$, persistia no campo jurídico uma profunda relação entre a Igreja e o Estado:

\begin{abstract}
A partir desse Código, a aplicação do direito canônico ficou proibida nos tribunais civis. Foram criados Tribunais Eclesiásticos que exerceriam essa função, porém, dada a sentença, cessava a jurisdição da Igreja, e a execução dos condenados à pena de morte ou aos demais castigos era feita pela justiça real, que recebia da instância eclesiástica a sentença de condenação (PIMENTEL, op. cit. p. 30).
\end{abstract}

Apesar de seu fraco desempenho prático, as leis escritas eram eficazes em ajudar a formar um imaginário social acerca das mulheres, que estabelecia uma forte conexão entre o comportamento pudico delas esperado e sua proteção por parte da lei, desde os tempos da hegemonia dos costumes visigóticos: era preciso que a comunidade referendasse sua reputação de "mulher honrada" para que o agressor pudesse ser punido (AZEVEDO, 2001).

\section{CONSIDERAÇÕES FINAIS}

As tradições jurídicas lusitanas vigoraram no Brasil por longos séculos, vendo-se refletidas, ainda hoje, em diversos artigos de nosso Código Civil. Essa influência passa também pela forma como nossos legisladores, juízes e magistrados compreendem a figura feminina desde os tempos coloniais. As Ordenações Filipinas possuem especial

\footnotetext{
${ }^{3}$ Entre eles podemos citar as Constituições Primeiras do Arcebispado da Bahia, 1707, de autoria de D. Sebastião Monteiro da Vide, que, de acordo com Pimentel, tinha vigência em todo o território colonial e era utilizado como base nos exercícios legais do Tribunal Eclesiástico (PIMENTEL, 2007 p. 30).
} 


\section{SEMINÁRIO DE PESQUISA EM CIÊNCIAS HUMANAS - SEPECH \\ Humanidades, Estado e desafios didático-científicos \\ Londrina, 27 a 29 de julho de 2016}

relevância neste sentido, devido ao fato de terem sido utilizadas desde a data de sua promulgação, até anos posteriores à nossa independência (AZEVEDO, 2001).

Nela, assim como em suas predecessoras, encontramos diversos artigos que visam a reforçar a ideia da submissão das mulheres aos seus maridos e respectivos tutores (pais, irmãos, tios), como algo natural e desejável. Sobre esse aspecto, não podemos deixar de notar a questão da necessidade de que estes concedam permissão ao casamento destas e ainda a guarda do dote pelo pai, quando solteira, e posteriormente pelo marido, sendo inúmeros os títulos que tratam da questão da proteção do dote, tentando evitar que este fosse gasto pelo cônjuge à revelia da esposa, uma vez que este tinha, em tese, o papel de ampará-la numa possível viuvez (FERNANDES, 2000).

Mesmo quando se pretende benevolente para com as mulheres, a lei salienta sua suposta inferioridade e recomenda que estas sejam protegidas devido à ideia de que teríamos uma suposta má formação do juízo, não podendo ser obrigadas a honrar compromissos, fiar negócios, vender bens, ter o 'privilégio' de pedir restituição por maus negócios contraídos pelos maridos ou por elas, quando se notasse que não haviam agido de má fé (AZEVEDO, 2001).

$\mathrm{O}$ livro $\mathrm{V}$ traz ainda a ideia de que os maridos possam, com direito assegurado por lei, castigar suas mulheres. Sendo a eles imposta pena pecuniária, isto é, multa para aqueles que as ferissem ou matassem, embora o mesmo título admita que possam ser excluídos das penas aqueles que agem "em legítima defesa, castigo a criado, discípulo, filho, escravo e... mulher" (AZVEDO, op. cit., p. 46).

A presente pesquisa encontra-se em fase de desenvolvimento, junto ao programa de mestrado em História Social da Universidade Estadual de Londrina, sendo estes alguns dos resultados parciais obtidos. Ao longo do trajeto espera-se compreender como esse conjunto legislativo atuou na construção dos imaginários de gênero no Brasil colonial, num esforço "civilizador" conjunto entre Estado Metropolitano e Igreja Católica.

\section{REFERÊNCIAS}

ANDRÉ, André Luiz Pedro. As Ordenações e o Direito Privado Brasileiro. Disponível em:

$<$ http://bdjur.stj.jus.br/jspui/bitstream/2011/18254/As_Ordena $\% \mathrm{C} 3 \% \mathrm{~A} 7 \% \mathrm{C} 3 \%$ B5es e o Direito Privado Brasileiro.pdf $>$ Acesso em 04/05/2016, às 20h30min.

ASSIS, RAMOS, SANTOS. A figura do herege nas Ordenações manuelinas e nas Ordenações Filipinas. Justiça \& História, Porto Alegre, v. 4, n. 7, p. 1-15, 2004.

AZEVEDO, Luiz Carlos de. Estudo Histórico sobre a condição jurídica da mulher no direito Luso-Brasileiro: desde os anos mil até o terceiro milênio. São Paulo: Editora dos Tribunais; Osasco, SP: Centro Universitário FIEO - UNIFIEO, 2001.

Introdução à história do direito. 4. ed. rev. e ampl. - São Paulo: Editora da Revista dos Tribunais, 2013. 


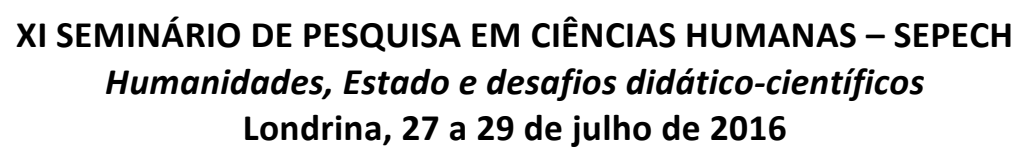

BICALHO, Maria Fernanda Baptista. Crime e castigo em Portugal e seu império. In: TOPOI - Revista de História do Programa de Pós Graduação em História Social da UFRJ, 2000, Rio de Janeiro, n. 1, pp. 224-231.

DEL PRIORE, Mary. Ao sul do corpo: Condição feminina, maternidades e mentalidades no Brasil Colônia. Rio de Janeiro: José Olympio; Brasília, DF: Edunb, 1993.

FERNANDES, Maria de Lurdes Correia. Literatura moral e discursos jurídicos em torno dos 'privilégios' femininos no século XVI em Portugal. Revista da Faculdade de Letras Línguas e Literaturas. Porto, XVII, 2000, pp. 403-418.

LARA, Silvia Hunold. Ordenações Filipinas. Livro V. São Paulo: Companhia das Letras, 1999.

LARA, Silvia Hunold; MENDONÇA, Joseli Maria Nunes (orgs.). Direitos e Justiças no Brasil: ensaios de História social. Campinas, SP: Editora da UNICAMP, 2006.

PIMENTEL, Helen Ulhôa. A ambiguidade da moral colonial: casamento, sexualidade, normas e transgressões. Univ. FACE, Brasília, v. 4, n. 1/2, p. 29-63, jan./dez. 2007.

SANTOS, Giovanna Aparecida Schittini. Direito e gênero: Rui Gonçalves e o Estatuto Jurídico das mulheres em Portugal no séc. XVI (1521-1603) Goiânia, 2007 (Dissertação de Mestrado).

SOIHET, Rachel. História das Mulheres. In: CARDOSO, Ciro Flamarion e VAINFAS, Ronaldo (orgs). Domínios da História - Ensaios de Teoria e Metodologia. Rio de Janeiro: Campus, p. 399-429, 1997.

VELASCO, Ignacio Maria Poveda. Ordenações do Reino de Portugal. Disponível em: http://www.revistas.usp.br/rfdusp/article/view/67236. Acesso em 05/04/16, às 19h52min. 